house. Lady Strangford, I believe it was, presented the police with the ambulance to which I think Dr. Morton refers in uncomplimentary terms, many years ago. It is now, of course, quite out of date. The St. Juhn Ambulance Association has met the want for the wealthy but for the general public in London there is practically no ambulance service. I am glad to say, however, that for Woolwich I have at last succeeded this year in obtaining an ambulance by means of public subscriptions. £90 were raised in this way and an excellent horse ambulance was purchased. This is vested in trustees and is lent to a local cab proprietor who keeps it and lends it out for use whenever required at the statutory cab fares, so that anybody requiring removal to hospital can obtain now a well-equipped ambulance at the same price and with the same ease as an ordinary cab. I would suggest to Dr. Morton that he should try to supply Hammersmith with an ambulance in the same way and shall be glad to give him further particulars of my experience on the matter in Woolwich if he desires it.

I am, Sirs, yours faithfully, SIUNEY DAVIES,

Woolwich, Dec. 2nd, 1902. Medical Officer of Health of Woolwich.

*** We believe that the whole question of ambulances in London will shortly be brought before the London County Council in a report made to the Council by Sir Wrilliam Collins.-ED. L.

\section{THE ANATOMY OF GLENARD'S DISEASE.}

To the Editors of THE LANCHT.

SIRS, -I have read with much interest your editorial annotation on the subject of the Anatomy of Glénard's Disease. ${ }^{\text {I }}$ I have not had an opportunity of perusing Dr. Arthur Keith's lecture which forms the subject of its comment. But whether the original mistake is due to Dr. Keith or to his commentator the annotation in THE LANCET now before me gives a decidedly erroneous view of some of the most important items in the mechanism of inspiration. In dealing with the action of the diaphragm we are told that: "He proceeds to correct some current and erroneous ideas as to the action of this muscle, and shows that it will enlarge the thoracic cavity mainly by lengthening it, by a depression of the heart and abdominal viscera when the muscles of the belly wall are slack, but by increasing in a proportionately greater measure the width and depth of the chest by the elevation of the lower ribs when the belly wall is resistant either by reanon of its good muscular development or from the artificial support of corsets." Now I will take the liberty of pointing out to your readers that the action of the diaphragm has long been understood by skilled anatomists much better than it seems to be by the writer of the sentence here quoted. Fixed as it is by its more stable (circumferential) attach ments to the xiphoid cartilage in front, to the upper three or four lumbar vertebra behind, and to the lower six (sometimes one more or less) ribs on either side, its muscular fibres converge to the central " cordiform" tendon, to a con. siderable portion of whose upper surface the pericardium is firmly adherent. The intermediate muscular fibres form curves-in the quiescent state-strongly convex upwards towards the thoracic cavity. The necessary result of this arrangement is that the contraction of the muscle as a whole converts the individual curves of its fibres into approximately straight lines. As a necessary consequence there is increased depth of the circumferential regions of the thorax. But the central tendon is only very slightly depressed; there is little change in the position of the heart or of the other contents of the "middle mediastinum." The simultaneous contraction of all the intercostal muscles in the act of inspiration raises and rotates the ribs, thereby widening the chest and, by throwing forwards the sternum, increasing its antero-posterior depth. But the four lower ribs are, at the same time, subjected to a peculiar in. fluence which would appear to have been entirely overlooked by your commentator. A very interesting and important muscle, the serratus posticus inferior, used to be described by the older physiologists as a "muscle of expiration"-and very wrongly. Arising from the last two dorsal and first two lumbar vertebræ, this muscle is inserted into the four lower ribs-outside the vertical line of their "angles." Its contraction, necessarily, draw's these ribs downwards and backwards. By acting simultaneously with the diaphragm and intercostal muscles, it has the effect of widening the basal section of the thorax, where most expansion is attainable. Whenever the movements of the lower ribs are trammelled by the contraction of the aboiominal muscles the necessary result is deficient expansion of the thoracic cavity. And when the widening of the loose segment of the thorax is limited, as it necessarily always is, by the use of tight corsets the result is very similar. Here lies the real evil of the $u-e$ of corsets so far as the function of respiration is concerned. But nature has, I must observe, rather liberally provided for difficulties of respiration in this region in case of the female section of the population. Thoracic expansion with them is mostly of the "superior thoracic" type ; and accordingly they are found in practice much more tolerant of constriction in this region than the enemies of corsets usually assume them to be. I have known some " wasp-waisted" ladies who could run, walk-aye, and even talk - faster than most of their female, or any of their male, rivals in these departments of physical exertion.

I am, Sirs, yours faithfully,

Dublin, Nov. 19th, 1902.

JoHN KNOTT, M.D. Dub.

** Dr. Knott is criticising a paper which he has not read. His remarks as to the action of the diaphragm are mostly academically correct, but had he read the paper he would have gathered that several of his premisses are probably incorrect, particularly that which assumes the relative immobility of the central tendon. As to the assertion that the lower ribs are drawn downwards and backwards by the simultaneous contraction of the diaphragm, intercostals, and serratus posticus inferior, it is sufficient to remark that clinicians who have opportunities of watching the isolated actions of muscles in disease are all agreed that the diaphragm eievates the lower ribs.--ED. L.

\section{SHOULD PNEUMONIA BE CLASSIFIED AMONG THE SPECIFIC INFECTIVE DISEASES ?}

To the Editors of THE LANCET.

SIRS, - At the present time there is an increasing tendency to separate pneumonia from the diseases of the lung and to classify it among the specific infective diseases. This has been done in some of the recent text-books of medicine and presumably it will be discussed by the nomenclature committee of the Royal College of Physicians of London. The matter is one of great importance, not only with regard to pneumonia, but also with regard to the nomenclature of diseases generally. Since a disease is not a definite entity but is a state involving the idea of motion we cannot classify diseases in the same way as we can classify definite objeets. We can only classify them according to the factors concerned in their causation or according to the effects produced by them. These two methods of classitication are both necessary and neither can replace the other. The definition of a disease depends on its classification and the significance of the name depends on the definition. The name, therefore, of a disease connotes either a definite causal factor, or an effect, whether the effect be an anatomical or a functional change or a symptom. In the case of the specific infective diseases the name connotes a specific extrinsic causal factor. Although we do not know the causal factors concerned in the production of many of these diseases, yet from the fact that they breed true and from other evidence there can be no doubt that specific agents are concerned in their causation. The term "syphilis," for instance, connotes a specific but unknown causal factor and does not connote any definite effect. Again, the term "tuberculosis" used to connote a definite effect-namely, the presence of tubercles in the organs; now, however, the term connotes a specific causal agentthe bacillus-whether or not tubercles are present in the organs, and it therefore excludes all cases in which the tubercles are present but which are not due to the specific baeillus. This alteration in the connotation has led to a confusion in the nomenclature with the result that we have had introduced the unsatisfactory term "pseudotuberculosis."

Now the term "pneumonia" connotes a certain effectnamely, a certain condition of the lung, and this condition is 
further specified by the use of adjectives, such as fibrinous, catarrhal, \&c. "Acute fibrinous pneumonia," therefore, connotes an acute fibrinous inflammation of the lung, whether this be caused by the pneumococcus, the streptococcus, the bacillus pestis, or other causal agent. The term, therefore, does not connote any specific causal agent and, in consequence, the disease pneumonia should not be classified among the specific infective diseases. If we wish to designate the disease characterised by having the pneumococcus as its specific causal agent we can do so by the term "pneumococcosis," thus following numerous precedents. If, however, we use the term "pneumonia" in this sense the term will be divorced from its proper meaning and we must never again use it to connote any condition of the lung, but must reserve it for those diseases which are characterised by the presence of the pneumococcus, whether or not the lung is affected. We should therefore have to include in it many cases of otitis media, pleurisy, pericarditis, \&c. We have, in fact, no more right to classify pneumonia among the specific infective diseases than we have to do the same with pleurisy, pericarditis, \&c.

It may be taken as a rule, to whicb there is no exception, that " a disease which is characterised by a specific effect is never characterised by a specific extrinsic causal agent," and, conversely, "a disease which is characterised by a specific causal agent is never characterised by a specific effect." Any alteration in the significance of accepted medical terms is bound to be followed by a hopeless confusion in medical nomenclature. It is to be hoped, therefore, that the nomenclature committee will refuse to sanction the proposed alteration in the significance of the term "pneumonia."-I am, Sirs, yours faithfully,

Charles Powell White, M.D. Camb.,

Nov. 21st, 1902 Assistant Pathologist and Demonstrator of Pathology at

\section{DEGREES FOR LONDON MEDICAL STUDENTS.}

To the Editors of THE LANCET.

SIRs,-In answer to the letter of "A Graduate and Diplomate" in THE LANCET of Nov. 29th, p. 1488, while begging to thank him for his remarks of sympathy, I would point out that all that has been said, as far as I know, in print upon the matter (and I have watched the question for some years) amounts to what is contained in the report of Sir William Jenner's committee, 1885 :

That the curriculum of study and the examinations to be undergone for the licence of the Royal College of Physicians of London and the diploma of the Royal College of 'Surgeons of England are aqual those required by most universities for degrees in medicine and those requery.

As regards his own experiences individual examples could be quoted where provincial graduates have failed to pass the final examinations of the Royal Colleges.

In conclusion, a perusal of the last list of successful candidates in the examination held for commissions in the Indian Medical Service shows that the provincial graduates are in no noted that this list includes several graduates of Cambridge. I am, Sirs, yours faithfully,

F. W. Collingtrood.

Devonshire-street, W., Nov. 28th, 1902

\section{THE ROYAL COLLEGE OF SURGEONS OF ENGLAND AND THE GENERAL MEDICAL COUNCIL.}

To the Editors of THE LANCHT.

SIRs, - All but those interested in maintaining the present oligarchy at this College must agree with $\mathrm{Mr}$. D. Vinrace as to the desirability of giving the Members the power to elect their (so-called) representative on the General Medical Council. I write, however, to assure Mr. Vinrace that nothing but an Act of Parliament or a new Charter can give the Members this power. What chance there is of obtaining the former can be easily imagined and the latter is never granted except on the application of the governing body for the time being. If Mr. Vinrace can induce the Council to make this application he will be more fortunate than others have been in the past. The "Society of Members" took counsel's opinion several years ago on this very point of the election of the College representative on the General Medical Council and was advised that under the existing Charters the appointment could only be made by the Council.

The amount of interest taken in College affairs is hardly indicated by the attendance at a meeting carefully deprived of all powers which properly pertain to it and held at an inconvenient hour at a busy time of year. That many Members still take an interest in their College is rather shown by the facts that 3245 have applied for the Council's report to be sent to them annually and that the number belonging to the "Society of Members" has more than doubled within the last year or so. However, we are fully conscious that it is futile to rely longer upon the proceedings at the annual meeting as the only means of inducing the Council to consider our claims and we hope shortly to initiate a more effective policy.-I am, Sirs, yours faithfully,

Dec. 1st, 1902.

W. G. DTCKINSON.

\section{THE UNIVERSITY OF LONDON AND THE ENGLISH ROYAL COLLEGES OF PHYSICIANS AND SURGEONS.}

\section{To the Editors of THE LANCET.}

SIRs,-I would like your permission to reply to Mr. Munro Scott's statement in THE LANCET of Nov. 15th, p. 1351, that "after all it is not desirable that every practitioner should" be of the highest rank-there must be the more ordinary class to attend the poorer part of the population "; and also to his suggestion that the Royal Colleges of Physicians of London and Surgeons of England should amalgamate with the Apothecaries' Hall to unitedly create an inferior order of practitioner. It must be very interesting for fathers who have been put to great pecuniary sacrifice on their sons' bebalf and to the sons who have toiled for many hard years to obtain their M.R.C.S. and L.R.C.P. to know, on Mr. Munro Scott's authority, that these qualifications are the stamp of an inferior grade of practitioner, who is only fit to be trusted to practise on "the poorer part of the population." Sir Frederick Treves once stated that any man who had filled the posts of house surgeon and house physician at the London Hospital was fit for any medical or surgical appointment in the world, and $\mathrm{I}$ have no doubt that eminent medical men of otherhospitals would make a similar statement in regard to those who have occupied similar posts elsewhere. Now these posts are usually held by men whose qualifications are the M.R.C.S. and L.R C.P., and who in many instances are prevented by outside circumstances alone from proceeding to their Fellowship, and yet these men, according to the insinuation of the Warden of the London Hospital, are fit only to attend "the poorer part of the population." On reading Mr. Munro Scott's effusion I at first came to the conclusion that the letter must have emanated from a layman, for I could not conceive of any professional man being so unprofessional as to suggest that he himself and a few equally "select" individuals were alone competent to attend the " rich portion of the population." But when I saw appended to his signature the fact that he is Warden of the London Hospital my diagnosis changed and I concluded that the writer must have been a London M.D. and F.R.C.S. Eng. (and perhaps even an F.R.S.) who from a lofty height of intellectual eminence and occupying a position of "splendid isolation" looked down with pity (not to say scorn) on those of his professional brethren whose cerebral centres were not so well academically represented as his own. But on looking in the Medical Directory I could not find the name of this gentleman who writes from " behind the scenes"-could not find that he even possessed the diplomas which he affects to despise, and so I presume he is not even qualified to attend "the poorer part of the population." Well, if his medical and surgical knowledge is not of a higher order than his comments on the qualifications of medical men this is perhaps a good thing for "the poorer part of the population." Comparisons are always odious, but I do not think that any fair-minded man competent to judge will deny that London medical students who study under the members of the staffs of the various metropolitan hospitals and who qualify with their M.R.C.S. and L.R.C.P. are in no way inferior in their professional knowledge to gentlemen who have graduated at our provincial universities. And certainly I think that any man who knows anything about 